\title{
The Model Building for the Influence of the Water Environment on Urban Tourism Ecological Capacity
}

\author{
Zuyong Wan \\ Business School, \\ Hohai University \\ Nanjing, China \\ Wanzy988@163.com;
}

\author{
Juqin Shen \\ Institute of Environmental Accounting and Asset \\ Management, Business School, \\ Hohai University \\ Nanjing, China \\ jqshen@hhu.edu.cn
}

\begin{abstract}
This article first define the concept of the urban water environment and city tourism environment capacity, and points out that the urban tourism environment capacity including urban tourism ecological capacity, urban tourism spatial capacity, urban tourism economy capacity and city tourism mental capacity, on the basis of which, the tourist ecological capacity of the influence factors were analyzed. And from the water environment of tourists' capital input and the relationship among the water environment of the city tourism ecological capacity of six son model and influence comprehensive model, in order to improve the water quality and water environment, promote the city tourism economy and here comes the theory basis.
\end{abstract}

Keywords-Urban Water Environment; Urban tourism environment capacity; Funding; Number of the tourists; Tourism economy

\section{I.INTRODUCTION}

As human beings' more and more intense to improve the quality of life, and improving survival demands of the environment, water resources will become the focus of the contradiction in the 21 st century. At present the city water is in shortage, water pollution, water environmental degradation problems have become the shackles of urban development. Therefore, the water more or less determines the scale of development of the city and the development direction.

January 29, 2011 the central committee of the communist party issued by the central committee of the $\mathrm{CCP}$ about to speed up the reform of the state council of the water conservancy development decision, in" Decision ", as the strict management of water resources speed up the transformation of the mode of economic development strategic move, the government pay attention to the protection by positive science of water based on the law, speed up the construction of the water-saving society, through the effective management make water environment have a significant change. 30 years of reform and opening up, China has rapid economic developments, but the urban water environment problems in China have become more obvious. As people living standard rise, residents' requirements of the quality of the urban water environment get also higher. People have realized the importance of urban water environment in the harmonious development of city and which has been kept an important position. Increasing urban water environment improvement of funds, in order to promote the improvement of the quality of the water environment, add urban tourism carrying capacity, could be beneficial for urban tourism economy of great practical significance.

\section{II.CITY TOURISM RESEARCH REVIEW AND RELATED CONCEPT DEFINITION}

\section{A. Studies Review}

Foreign urban tourism research started in the $1960 \mathrm{~s}$, which can be traced back to the earliest American scholars Satisfied, in 1964 he in his book "the United States tour of the research of urban and rural imbalances" in the first expounds the importance of the urban tourism research, pointed that the urban tourism research in tourism is the field that never be ignored. After the $1970 \mathrm{~s}$ the importance of urban tourism gradually began to be known for western scholars, $1980 \mathrm{~s}$ to $90 \mathrm{~s}$, the urban tourism research has been further developed, research scope and gradually expand the areas too, until the $1990 \mathrm{~s}$ city tourism truly as an important and unique aroused the attention of the field, and for urban tourism research is the European and American countries the situation also shifting, being broken. As the world scope the acceleration of urbanization, Oceania, Asia, Africa and other countries and areas of the implementation of the old city of industrial structure, the new city constantly emerging, urban tourism research also then begin to start. World tourism scholars and urban studies experts have flocked to join the ranks of the urban tourism research, from every region of the voice of the urban tourism research situation increasingly active.

Overview of urban tourism research at home and abroad, since the $1990 \mathrm{~s}$, domestic and foreign academic circles to the urban tourism research vision gradually moving towards the open, and in the theories and concepts in the research of the system also scaled up to a new level. The author has been given the important theoretical background by Domestic and overseas scholars in the field of research results. But on the research contents of domestic and foreign scholars can see that, so far, no related to water environment on city tourism impact study, and water environment quality 
is one of the most important influence factors of urban tourism in one of the urban tourism ecological capacity for the one of the elements, therefore, through the water environmental capital input and the number of the relationship between tourism model building research of urban water environment of tourism ecological capacity of the influence has theoretical significance and practical operability.

\section{B. Related concept definition}

Through the relationship between water environmental capital input and the number of the tourism model building research of urban water environment of tourism ecological capacity of the influence from the city tourism must define the water environment and city view urban tourism capacity. So the study could be specific and accurate.

\section{1) Urban water environment}

"China water resources encyclopedia of urban water environment of the general will be defined as: the city natural biological survival of water environment, the ability to resist disasters, degree of water supply, water quality conditions, water conservancy project with the surrounding landscape harmonious degree and so on many items content. $\mathrm{Xu}$ from sustainable residential area from the meaning of water environment, and points out that residential area should include water environment the connotation and extension. Connotation of ecological residential area is in the interior architectural water system, effluent water system, system, landscape water system, rain water system and other components of the water environment system. The extension is mainly of residential areas in the geographic location, environment, climate; the vegetation ecosystem; the wetland environment can be created and the sustainable utilization of ecological energy auxiliary system. Residential water environment is the connotation and denotation of universality and individuality relationship.

This article from the point of view of the city tourism, based on the theory of environmental economics, to define the city water environment, the author has an view that the city water environment is internal and around the city of urban water system of relative, a city tourism and associated with the water environment and water environment of urban tourism has a great influence on the water as the main aspects or in the urban tourism.

\section{2) Urban tourism environment capacity}

Wan Youqing think that traveling environmental capacity is a point to tourist now in a state, and environment structure combination of contemporary and future generations will not occur under the premise of harmful changes, in a certain period with the ecological environment of the tourism resources, the load of space and the economic load of psychological factors of the four aspects of the capacity of an organic whole. The city tourism environment capacity et al is to point to in a certain period, some state condition, the city the environment of the scenic area could take tourist economy activity. It is in a city tourism resources that the ecological status will not occur and future generations of contemporary people harmful effects, and can meet the precondition of tourists, a tourist city in a certain time of the biggest number of visitors can accommodate.

In view of the above analysis, this article from the point of view of urban water environment definition tourism environment capacity that city tourism environment capacity of water environment is the change of the tourism carrying capacity corresponding will happen relatively should change degree of analysis, the change of the tourism carrying capacity will cause the change of the tourists, and the city tourism bring change. According to six elements of tourism, and it will be for the four categories that urban tourism ecological capacity, urban tourism spatial capacity, urban tourism economy capacity and city tourism mental capacity.

\section{III.INFLUNENCE FACTORS ANALYSIS OF URBAN TOURISM ECOLOGICAL CAPACITY}

Tourism ecological capacity is measured by the main tourist area water environmental capacity, atmospheric environmental capacity, environmental solid waste capacity, vegetation environmental ecology four factors restricting the capacity. Among them: the water environmental capacity is to point to in meet the standards for water environment quality, at the request of the maximum allowed water pollution load, also called on water carrying capacity. The water environmental capacity by a series of factors, such as water resources, self-purification capability, water environment target function, sewage, mode, the degradation of pollutants coefficient, water quality, water diversion boundary. Water environment changes, will cause the change of these factors, then affects the water environmental capacity; ultimately affect the city tourism ecological capacity.

\section{Water resources}

The water resources quantity is the foundation of the water environmental capacity, water quantity sufficient to ensure tourist area of the water environmental capacity fully. Water resources for the development of the city have made an important limiting factor. Here is the research object to be called "water resources", not "water quantity", because from the point of view of ecological environmental protection, and not all of the water resources are available for city life, production of use. The improvement of the water environment of ecological capacity is the effect of water, as the improvement of the environment increases, the improvement of the quality of water supply, which includes industrial and agricultural production and the improvement of living water. Water the improvement of the environment can ensure that the quality of the water supply, thus ensuring the industrial water and the stability of the life in the water.

\section{Since the net ability and the degradation of pollutants coefficient}

The improvement of the water environment can improve water environment for the degradation of pollutants ability, so as to improve the water environment of self-purification capability. Since the increasing capacity of net environment 
can reduce the cost of human performance, improve the ability of the net income, namely the increased value of water environmental capacity. The water environment of improving the environment of self-purification capability still can bring significant comprehensive performance.

\section{E. Drainage way and the drainage outlet position laid}

Drainage way and the drainage outlet position laid, the local pollutants mixed diluted influence. The improvement of the water environment, on the one hand, can reduce pollution management, investment in facilities; reduce the burden of the government and the enterprises. On the other hand, can also have no impact on the premise of the sustainable development of the industry to appropriately increase the producing pollution emissions, reduce the burden of the enterprise, and increase the income.

\section{F. Boundary water diversion water quality}

The condition of the boundary of the water quality of water diversion water quality boundary is beneficial to the change of the water environmental capacity which is also important. The water environment to improve it can improve the urban border water diversion water quality, so as to improve the unit time related the maximum allowed dirt, water quantity, and the water environmental capacity have an impact.

\section{IV.MODEL BUILDING FOR INFLUENCE OF WATER ENVIRONMENT ON URBAN TOURISM ECOLOGICAL CAPACITY}

\section{G. Model building ideas}

The water environmental capacity before building a comprehensive model according to the first landscape environment water ecological risk indicators pollutants, on the basis of which, the son model, the son model mainly includes pollutants model pollutant capacity model, and the fund investment model. The main pollutants model including urban residents pollutants model, tourism pollutants tourists model; The main pollutant capacity model including $\mathrm{V}$ class IV class to improve water pollutants capacity increases model, a bad V kind of water for ascension of pollutant capacity increase water IV model; Money into model mainly includes $\mathrm{V}$ kind of water promoted to IV class water capital input model, unhealthy $\mathrm{V}$ kind of water promoted to IV class water capital input model. In child model is built based on the water environment of the net effect from consideration, according to the input/output quality of conservation building integrated model, and reference value and standard model parameters are given, finally give the number of tourism and the relationship between capital investment.

\section{H. Models Building}

\section{1) Sub-models building \\ a)Pollutant emissions model}

Firstly, pollutant emissions model of urban residents living sources.

The domestic sewage of urban residents includes not only sewage generated by urban residents in their daily lives, but also the sewage generated by the residents' services and other services sectors. Sewage collected by the municipal pipe network into the urban sewage treatment plant are processed and then discharged. Existing urban sewage discharge standards mainly have four standards, primary standard a, primary standard B, secondary standard, and standard of grade III respectively, in which primary standard $\mathrm{A}$ is the most stringent and standard of grade III the most lenient. The main emission standards of sewage treatment plants in Jiangsu, Zhejiang and Shanghai are primary standard A and primary standard B. The pollutants in water are mostly from the sewage plants' effluents and untreated sewage. Therefore the specific model is available based on the above analysis; such as shown in formulate 1:

$$
G_{p}=365\left[\frac{\alpha N Q C_{A}}{100}+\frac{\beta N Q C_{B}}{100}+\frac{\delta N Q C_{0}}{100}\right]
$$

Where $G_{p}$ — the annual emissions of urban residents living pollutants, $\mathrm{kg} /$ year; $\alpha$-the discharge proportion of effluents treated by urban sewage treatment plants according to the primary standard $\mathrm{A} ; \beta$ - the discharge proportion of effluents treated by urban sewage treatment plants according to the primary standard $\mathrm{B} ; \delta$ - the discharge proportion of untreated effluents emitted into the water directly, in which $\alpha+\beta+\delta=1 ; N$ - the resident population of urban residents, million people; $Q$-fixed sewage of urban residents, $1 /$ (capita.day); ${ }^{C_{A}}$ - the concentration of pollutants in primary standard A according to the "Pollutant Emission Standards of Municipal Sewage Treatment Plant", mg/l; $C_{B}$ - the concentration of pollutants in primary standard B according to the "Pollutant Emission Standards of Municipal Sewage Treatment Plant", mg / 1.

Secondly, tourists' pollutant emissions model in travelling.

Pollutant emissions by tourists during travelling mainly mean pollutants emitted into outside environment or other municipal public facilities which are generated by the accommodation and catering industry, and then processed by its own disposal facilities or treatment facilities, as shown in formula 2:

$$
G_{p}^{\prime}=\frac{\alpha N^{\prime} Q C_{A}}{100}+\frac{\beta N^{\prime} Q C_{B}}{100}+\frac{\delta N^{\prime} C_{0}}{100}
$$

Where $G_{p}^{\prime}$ — the annual pollutants emissions from tourists, $\mathrm{kg} /$ year; $N^{\prime}$ — the number of visitors, million people; $Q^{\prime}$ _ sewage quota from tourists/ (capita. day).

\section{b) The pollutants capacity model}

The water pollutants capacity will increase with the improvement of water environmental quality of urban landscape, and the measures to improve water environment of landscape specifically include two categories: to upgrade 
water in Class V to Class IV 、 inferior standard V to Class IV . The water quality improved can contain more pollutants in order to meet the requirements of scenic water quality standard.

Firstly, the increased capacity of pollutants model by upgrading the water in Class $\mathrm{V}$ to Class IV, as shown in formulate 3 :

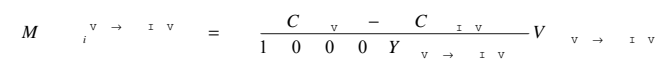

Where $M_{i}^{\mathrm{V} \rightarrow \mathrm{IV}}$ the increased capacity of pollutants by upgrading the water in Class $\mathrm{V}$ to Class IV, $\mathrm{kg} /$ year;

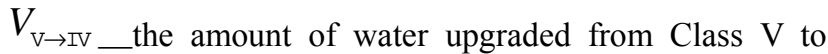
Class IV, cubic meters; $C_{\mathrm{V}}$ _the pollutant concentration of water in Class $\mathrm{V}, \mathrm{mg} / \mathrm{L} ; C_{\mathrm{IV}}$ the pollutant concentration of water in Class IV, $\mathrm{mg} / \mathrm{L} ; Y_{\mathrm{V} \rightarrow \mathrm{IV}}$ _the usage life of water upgraded from Class V to Class IV, year.

Secondly, the increased capacity of pollutants model by upgrading the water in inferior standard V to Class IV, as shown in Equation 4:

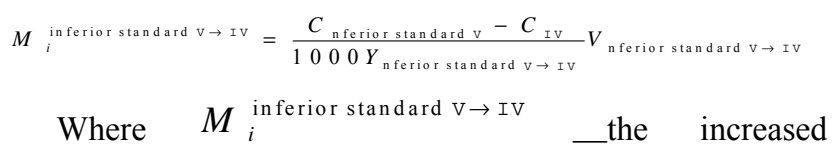
capacity of pollutants by upgrading the water in inferior

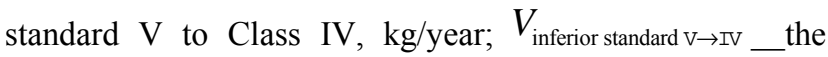
amount of water upgraded from inferior standard $\mathrm{V}$ to Class IV, cubic meters; $C_{\text {inferior standard } \mathrm{V} \rightarrow \mathrm{IV}}$ _the pollutant concentration of water in inferior standard $\mathrm{V}, \mathrm{mg} / \mathrm{l}$; $Y_{\text {inferior standard } \mathrm{V} \rightarrow \mathrm{IV}}$ the usage life of water upgraded from inferior standard V to Class IV, year.

\section{c) Fund input model}

The fund input model gives the relationship between the total funds input and water quality improvement, including two aspects: the first is the capital input model to upgrade water in Class V to Class IV, and the second is the capital input model to upgrade water in inferior standard V to Class IV.

Firstly, the capital input model to upgrade water in Class V to Class IV, as shown in formulate 5:

$$
T_{\mathrm{V} \rightarrow \mathrm{IV}}=\lambda_{\mathrm{V} \rightarrow \mathrm{IV}} V_{\mathrm{V} \rightarrow \mathrm{IV}}
$$

Where $T_{v \rightarrow \mathbb{N}}$ _the total funds input to upgrade water in

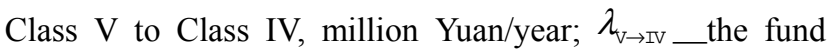
input every cubic meter to upgrade water in Class $\mathrm{V}$ to Class IV, million yuan/ (cubic meters. year).

Secondly, the capital input model to upgrade water in inferior standard V to Class IV, as shown in formulate 6:

$$
T_{\text {nferior standard } \mathrm{V} \rightarrow \mathrm{IV}}=\lambda_{\text {nferior standard } \mathrm{V} \rightarrow \mathrm{IV}} V_{\text {nferior standardV } \rightarrow \mathrm{IV}}
$$

Where $T_{\text {inferior standard } \mathrm{V} \rightarrow \mathrm{IV}}$ — the total funds input to upgrade water in inferior standard $\mathrm{V}$ to Class IV, million Yuan/year; $\lambda_{\text {inferior standard } v \rightarrow \text { Iv }}$ — the fund input every cubic meter to upgrade water in inferior standard $\mathrm{V}$ to Class IV, million Yuan/ (cubic meters. year).

\section{2) Integrated model building}

a) Integrated model of the increased number of tourists and fund input to water environmental governance

The integrated model of the increased number of tourists and fund input to water environmental governance is to combine six sub-models organically, which is mainly based on the principle of conservation of mass and considering the self-purification of water. According to the amount of pollutants into water discharged by urban residents and tourists each year should be balanced with the increased capacity to water pollutants resulting from water quality enhancement, so as the mass conservation in formula 7 :

$$
\mu\left(G_{p}+G_{p}^{\prime}\right)=M_{i}^{\mathrm{V} \rightarrow \mathrm{IV}}+M_{i}{ }_{i}^{\text {inferiorstandard } \mathrm{V} \rightarrow \mathrm{IV}}
$$

Formula 1, 2, 3, 4, 5, 6 are substituted into 7 , is formula 8 :

$$
\begin{aligned}
& \mu\left\{365\left[\frac{\alpha N Q C_{A}}{100}+\frac{\beta N Q C_{B}}{100}+\frac{\delta N Q C_{0}}{100}\right]+\frac{\alpha N^{\prime} Q^{\prime} C_{A}}{100}+\frac{\beta N^{\prime} Q^{\prime} C_{B}}{100}+\frac{\delta N^{\prime} Q^{\prime} C_{0}}{100}\right\} \\
& =\frac{C_{\mathrm{V}}-C_{\mathrm{IV}}}{1000 Y_{\mathrm{V} \rightarrow \mathrm{IV}}} V_{\mathrm{V} \rightarrow \mathrm{IV}}+\frac{C_{\text {inferior standard } \mathrm{V}}-C_{\mathrm{IV}}}{1000 Y_{\text {inferior standard } \mathrm{V} \rightarrow \mathrm{IV}}} V_{\text {inferior standard } \mathrm{V} \rightarrow \mathrm{IV}}
\end{aligned}
$$

Formula 5, 6, 7 are substituted into 8 , is formula 9:

$$
\begin{aligned}
& \mu\left\{365\left[\frac{\alpha N Q C_{A}}{100}+\frac{\beta N Q C_{B}}{100}+\frac{\delta N Q C_{0}}{100}\right]+\frac{\alpha N^{\prime} Q^{\prime} C_{A}}{100}+\frac{\beta N^{\prime} Q^{\prime} C_{B}}{100}+\frac{\delta N^{\prime} Q^{\prime} C_{0}}{100}\right\} \\
& =\frac{C_{\mathrm{V}}-C_{\mathrm{IV}}}{1000 Y_{\mathrm{V} \rightarrow \mathrm{IV}}} \cdot \frac{T_{\mathrm{V} \rightarrow \mathrm{IV}}}{\lambda_{\mathrm{V} \rightarrow \mathrm{IV}}}+\frac{C_{\text {in ferior standard }}-C_{\mathrm{IV}}}{1000 Y_{\text {inferior standard } \rightarrow \mathrm{IV}}} \cdot \frac{T_{\text {inferior standard } \mathrm{V} \rightarrow \mathrm{IV}}}{\lambda_{\text {inferior standard } \mathrm{V} \rightarrow \mathrm{IV}}}
\end{aligned}
$$

After conversion results in formulate 10. Formulate 10 shows the relationship between the number of tourists $\left(N^{\prime}\right)$ and funds input $\left(T_{\mathrm{v} \rightarrow \mathrm{V}} 、 T_{\text {inferior standard } \mathrm{V} \rightarrow \mathrm{IV}}\right)$ needed by water quality enhancement.

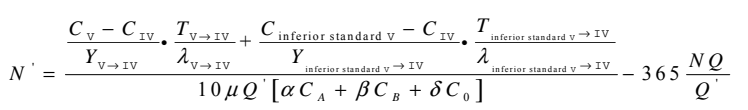

The indicator pollutants we selected in water are chemical oxygen demand (COD), ammonia (NH3-N), total nitrogen (TN), and total phosphorus (TP). Due to the differences in the increased number $\left(N^{\prime}\right)$ of tourists calculated by each indicator pollutant, so in actual circumstances we just take the least increased number of tourists- $N_{\text {min }}^{\prime}$.

\section{b) The most credible increase in the number of tourists}

The relationship between the number of tourists( $N^{\prime}$ ) calculated by COD indicators and fund input $\left(T_{v \rightarrow N}\right.$ 、 $T_{\text {inferior standard } v \rightarrow \text { IV }}$ ) needed by water quality enhancement is shown in the formulate 11, and in which are relevant parameters of COD indicators, like $C_{\mathrm{A}}, C_{B}, C_{0}, C_{\mathrm{v}}, C_{\mathrm{rv}}, \mathrm{C}_{\text {inferior standard V }}$. 


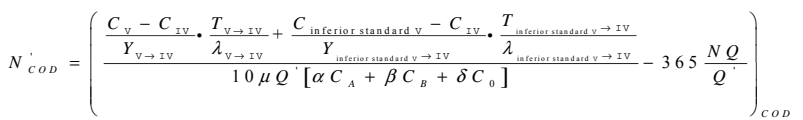

The relationship between the number of tourists( $N^{\prime}$ ) calculated by $\mathrm{NH}_{3}-\mathrm{N}$ indicators and fund input $\left(T_{v \rightarrow \mathrm{v}}\right.$ 、 $T_{\text {interior standara } v \rightarrow I V}$ ) needed by water quality enhancement is shown in the formulate 12 , and in which are relevant parameters of $\mathrm{NH}_{3}-\mathrm{N}$ indicators, like $C_{A}, C_{B}, C_{0}, C_{\mathrm{v}}, C_{\mathrm{IV}}$, $\mathrm{C}_{\text {inferior standardV }}$.

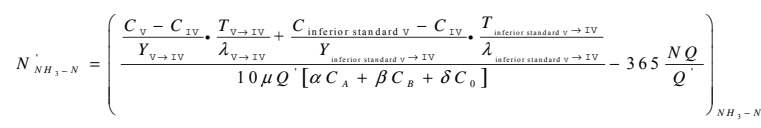

The relationship between the number of tourists $\left(N^{\prime}\right)$ calculated by TN indicators and fund input $\left(T_{v \rightarrow N}\right.$ 、 $T_{\text {inferior standard } \mathrm{V} \rightarrow \mathrm{IV}}$ ) needed by water quality enhancement is shown in the formulate 13, and in which are relevant parameters of $\mathrm{TN}$ indicators, like $C_{\mathrm{A}}, C_{B}, C_{0}, C_{\mathrm{V}}, C_{\mathrm{IV}}$, $\mathrm{C}_{\text {inferior standardV }}$.

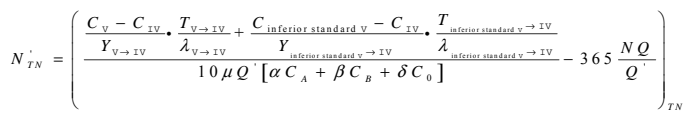

The relationship between the number of tourists( $N^{\prime}$ ) calculated by TP indicators and fund input $\left(T_{v \rightarrow N} 、 T_{\text {inferio standard } \mathrm{V} \rightarrow \mathrm{N}}\right)$ needed by water quality enhancement is shown in the formulate 14, and in which are relevant parameters of TP indicators, like $C_{A}, C_{B}, C_{0}, C_{\mathrm{v}}, C_{\mathrm{IV}}$.

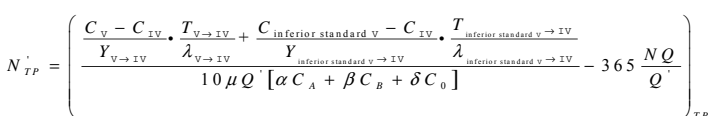

The actual increase in the number of tourists $N_{\min }^{\prime}$ is shown in the formulate 10

$$
N_{\mathrm{m} \text { in }}^{\prime}=\mathrm{m} \text { in }\left[N_{C O D}^{\prime} ; N_{N_{H_{3}-N}}^{\prime} ; N_{T N}^{\prime} ; N_{T P}^{\prime}\right]
$$

\section{c.the explanation of relevant parameters of model}

formulate 10 shows the relationship between the number of tourists $\left(N^{\prime}\right)$ and fund $\operatorname{input}\left(T_{v \rightarrow \mathbb{N}} 、 T\right.$ $\rightarrow$ Iv ) needed by water quality . The model parameters are shown in Table 1 , Table 2.

\section{Some explanations of the parameters}

- The Number of urban population is from the sixth national census in 2010 Communiqué on Major Data (Jiangsu, Shanghai, and Hangzhou)

- Per capita sewage quota Q not only include living sewage discharge, but also include residents service and other services sewage discharge, the specific numerical reference "outdoor drainage design code (GB50014-2006)
- Per capita sewage quota Q, Correction coefficient of water self-purification $\mu$, empirical parameter, per cubic meter invested in promoting Class $\mathrm{V}$ water to class IV water, per cubic meter invested in promoting inferior standard $\mathrm{V}$ water to class IV water

- The following data should be sea in "China reclaimed water market analysis report (2010)"of China water net: the ratio $\alpha$ of Urban sewage treatment plant deal with the effluent according to A standard water discharge, the ratio $\beta$ of urban sewage treatment plant deal with the effluent according to $\mathrm{B}$ standard water discharge, the

\begin{tabular}{|c|c|c|c|c|c|c|c|c|c|c|}
\hline \multirow{2}{*}{ tric } & $C_{0}$ & $C_{A}$ & $C_{B}$ & $C_{\text {IV }}$ & $C_{V}$ & $C_{\text {inferiorstandardV }}$ & $Y_{V \rightarrow I V}$ & $\begin{array}{l}\begin{array}{l}Y_{\text {inferior }} \\
\text { standardV } \rightarrow \text { IV }\end{array} \\
\text { sand }\end{array}$ & $\lambda_{V \rightarrow I V}$ & $\begin{array}{l}\lambda_{\text {inferior }} \\
\text { standardV } \rightarrow \text { IV }\end{array}$ \\
\hline & \multicolumn{6}{|c|}{$\mathrm{Mg} / \mathrm{I}$} & \multicolumn{2}{|r|}{ year } & \multicolumn{2}{|c|}{$\begin{array}{l}\text { Ten } \\
\text { yuan(RMB)/cubic } \\
\text { meter }\end{array}$} \\
\hline COD & 400 & 50 & 60 & 30 & 40 & 50 & 10 & 20 & $3.5 \times 10^{-5}$ & $1.05 \times 10^{-4}$ \\
\hline $\mathrm{NH}_{3}-\mathrm{N}$ & 20.0 & $5^{(1)}$ & $8^{(1)}$ & 1.5 & 2.0 & 3.0 & 10 & 20 & $3.5 \times 10^{-5}$ & $1.05 \times 10^{-4}$ \\
\hline $\mathrm{TN}$ & 40.0 & 15 & 20 & $1.5^{3}$ & $2.0^{3}$ & 3.0 & 10 & 20 & $3.5 \times 10^{-5}$ & $1.05 \times 10^{-4}$ \\
\hline TP & 3.0 & $0.5^{2}$ & $1.0^{2}$ & $0.1^{3}$ & $0.2^{3}$ & 0.3 & 10 & 20 & $3.5 \times 10^{-5}$ & $1.05 \times 10^{-4}$ \\
\hline
\end{tabular}
ratio $\delta$ of the sewage account for untreated sewage discharged directly into water bodies

TABLE I. GENERAL PARAMETRIC

Note: (1) NH3-N is the emissions limits when water temperature $>12{ }^{\circ} \mathrm{C}$ (the limits when below $<12{ }^{\circ} \mathrm{C}$ the limits when); (2) the TP values for the discharge limits after the expansion of the wastewater treatment plant on January 1, 2006 (less than the limits before January 1, 2006); (3)TN, TP values for lake, libraries allow limits (below river limit)

TABLE II. DIFFERENT CITY CORRESPONDING PARAMETER TABLE

\begin{tabular}{|c|c|c|c|c|c|c|c|c|}
\hline \multirow{2}{*}{ city } & $\mathbf{N}$ & $\mathbf{Q}$ & $\mathbf{Q}^{\prime}$ & $\boldsymbol{\alpha}$ & $\boldsymbol{\beta}$ & $\boldsymbol{\delta}$ & $\boldsymbol{\mu}$ \\
\hline Nanjing & 800.47 & $350^{1}$ & 200 & $50 \%$ & $35 \%$ & $15 \%$ & 0.2 \\
\hline & The thousand people & \multicolumn{2}{|c|}{$\mathbf{L} /$ (people, day) } & \multicolumn{4}{|c|}{} \\
\hline Wuxi & 637.26 & 350 & 200 & $60 \%$ & $30 \%$ & $10 \%$ & 0.2 \\
\hline Suzhou & 1046.60 & 350 & 200 & $60 \%$ & $30 \%$ & $10 \%$ & 0.2 \\
\hline Hangzhou & 870.04 & 350 & 200 & $30 \%$ & $40 \%$ & $20 \%$ & 0.2 \\
\hline Shanghai & 2301.91 & 350 & 200 & $30 \%$ & $55 \%$ & $15 \%$ & 0.2 \\
\hline
\end{tabular}

Note:(1)including residents sewage and the third industry wastewater two parts

\section{V.CONCLUSIONS}

Governance of the water environment is a long process, water quality improvement are the consequences of years of governance, in recent years, the state invested heavily in the improvement of water environment, to bring the possibility to greatly enhance water quality. And these investments need a longer time to achieve the desired effect. Funding invested in the water environment will inevitably drive economic development, and there is a definite relation between tourism economy and water environment improvement, through the analysis, Funding invested in the water environment reach a certain scale, the improvement of water quality is obvious, and also offer powerful environmental protection for tourism.

\section{ACKNOWLEDGEMENTS}

This paper is the periodical achievement of Resources and Environment Accounting, one of the provincial key 
discipline (Business and Management, NO: 2084-H08002) of Jiang Su Province.

\section{REFERENCES}

[1] Environmental Protection Ministry of national standards. Surface water environmental quality standards [S], 2002.

[2] Environmental protection, national standards of urban sewage treatment plant pollutant emission standards [S], 2002.

[3] Ministry of Construction, National Institute of Standards and outdoor drainage design specification [S], 2006.
[4] Jiangsu Province Bureau of Jiangsu Province in 2010 the sixth national census data communique .2010, Avaiable from: http://www.jssb.gov.cn/jstj/djgb/qsndtjgb/201105/t20110503115227.htm

[5] Zhejiang Bureau of Statistics, Zhejiang Province, in 2010 the sixth national census data communique .2010, Avaiable from: http://www.zj.stats.gov.cn/art//2011/56/art-165..html.

[6] Shanghai Municipal Bureau of Statistics, 2010, Shanghai Sixth national census data communique .2010, Avaiable from: http://www.statssh.gov.cn/sjfb//201105/218819.html. 